JOEAI (Journal of Education and Instruction)

Volume 2, Nomor 1, Juni 2019

e-ISSN : 2614-8617

p-ISSN : 2620-7346

DOI : https://doi.org/10.31539/joeai.v2i1.569

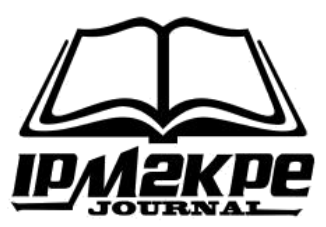

\title{
EFEKTIFITAS PENGGUNAAN MEDIA LCD DALAM MEMOTIVASI BELAJAR PESERTA DIDIK
}

\author{
Muhamad Agus Sugiarto \\ IKIP PGRI Jember \\ muhammadagussugiarto@gmail.com
}

\begin{abstract}
ABSTRAK
Tujuan penelitian ini adalah untuk mengetahui efektifitas penggunaan media LCD dalam memotivasi belajar peserta didik. Teknik pengumpulan data penliti menggunakan beberapa teknik yakni observasi, angket dan wawancara. Adapun langkah penyajian data yaitu; (1) reduksi data, merangkum data yang diperoleh sehingga memberikan gambaran yang lebih jelas, (2) Penyajian data, peneliti menampilkan data berupa teks naratif yang didukung hasil angket yang sudah diuji coba di lapangan, (3) Verifikasi, penarikan kesimpulan dan verifikasi dengan tujuan dapat menjawab rumusan masalah. Hasil penelitian, setiap siswa mempunyai keinginan untuk giat belajar, namun banyak faktor yang mempengarui peserta didik sehingga menjadikan malas untuk belajar, hal ini menjadi tugas tenaga pengajar dan orang tua untuk bisa memotovasi. Adapun faktor pendukung dan penghambat penggunaan LCD proyektor adalah sebagai berikut (1) faktor pendukung: tenaga pendidik yang memiliki keahlian dari pelaksanaan pelatihan, kesadaran orang tuan terhadap Pendidikan, tempat belajar yang kondusif dan bersih, sarana dan prasarana yang lengkap. (2) faktor penghambat: masih ada tenaga pendidik yang belum bisa mengopersaikan teknologi sehingga tidak dapat menggunakan media LCD, mash minimnya pelatihan untuk tenaga pengajar terkait penyajian materi yang menarik, masih sulitnya tenaga pendidik untuk menggunakan metode baru. Simpulan, penggunaan media LCD dapat memotivasi siswa dalam belajar
\end{abstract}

Kata Kunci : Penggunaan Media LCD, Motivasi Belajar, Peserta Didik

\section{ABSTRACT}

The purpose of this study was to determine the effectiveness of the use of LCD media in motivating student learning. Researcher data collection techniques used several techniques namely observation, questionnaire and interview. The steps to present data are; (1) data reduction, summarizing the data obtained so as to provide a clearer picture, (2) Presentation of data, researchers display data in the form of narrative texts supported by questionnaire results that have been tested in the field, (3) Verification, drawing conclusions and verification with the goal can answer the problem formulation. The results of the study, each student has a desire to study hard, but many factors affect students so as to be lazy to learn, this is the task of teachers and parents to be able to motivate. The factors supporting and inhibiting the use of LCD projectors are as follows (1) supporting factors: educators who have expertise from conducting training, awareness of the masters of Education, a conducive and clean learning place, complete facilities and 
infrastructure. (2) inhibiting factors: there are still educators who have not been able to operate technology so they cannot use LCD media, mash lack of training for teaching staff related to the presentation of interesting material, it is still difficult for educators to use new methods. In conclusion, the use of LCD media can motivate students to learn.

Keywords: Use of LCD Media, Learning Motivation, Learners

\section{PENDAHULUAN}

Teknologi yang perkembang pesat saat ini, dimana kita sudah masuk di era industry 4.0 (revolusi industry generasi keempat) yang di tandai denga adanya super computer, kendaraan tanpa supir, robot pintar. Di Indonesia sejak tahun 2011 revolusi industru 4.0 sudah dilakukan dengan adanya peningkatan koneksivitas, terjadi lompatan yang sangat besar di bidang industry yakni penggunaan teknologi informasi dan komunikasi yang dimanfaatkan sepenuhnya, dengan menggunakanya dalam proses produksi sampai pemasaran sehingga melahirkan model bisnis baru yang berbasis digital, sepertihalnya online shopping.

Dampak perkembangan teknologi tentunya tidak hanya dalam bidang industry saja, seperti yang sudah dipaparkan di atas melainkan disegala bidang termasuk di bidang Pendidikan. Dampak tersebut seperti metode mangajar, karakteristik siswa, dan perangkat pembelajaran. Sehingga perlu adanya upaya pembaharuan dan pemanfaatan teknologi dalam Pendidikan. Peran guru setidaknya bisa menggunakan alat teknologi yang sederhana dalam proses belajar mengajar demi tercapainya tujuan pembelajaran yang diharapakan.

Usaha untuk meningkatkan hasil belajara siswa sanagt perlu dilakukan agar menghasilakan Sumber Daya Manusia yang siap menghadapi tantangan perkembangan teknologi/ revolusi industry 4.0. usaha tersebut tentunya tidak lepas dari tanggunga jawab tenaga kependidikan, terutama guru yang secara langsung membina siswa dalam proses belajara mengajar.

Penggunaan media pembelajaran sangatlah penting dalam kegiatan belajara mengajar, menurut Sudjana (2000) Media pembelajaran memiliki manfaat sebagai penarik perhatian siswa sehingga timbul motivasi, bahan pelajaran akan lebih jelas maknanya sehingga dapat lebih dipahami, metode mengajar kan bervarisi, dan siswa banyak melakukan kegiatan belajar (Suryanto, 2005). Tetapi pada kenyataannya guru masih menggunakan gaya mengajar konvensional dan tidak memanfaatkan teknologi sebagai media pembelajaran.

Madrasah Aliyah ASHRI Jember khususnya mata pelajaran Bahasa Indonesia pokok pembahasan Drama kelas XIIA A pembelajaran kurang berhasil untuk menggairahkan motivasi peserta didik yang ditunjukkan dengan ekspresi secara verbal juga dari hasil belajar siswa. Kurangnya hal tersebut karena guru tidak mengembangkan media dalam kegiatan belajar mengajar. 
Berdasarkan hasil wawancara dengan tenaga pengajar Bahasa Indonesia kelas XIIA, bahwa kegiatan belajar mengajar sudah menggunakan media LCD proyektor dan sudah tersedia di maing-masing kelas. Hal ini dimaksudkan untuk meningkatkan proses belajar mengajar serta membantu tenga pengajar menyampaikan informasi. kendala yang didapati adalah kurangnya pemahaman tentang teknologi, sehingga tidak dapat membuat penyajian materi yang menarik, adapun tujuan penelitian ini adalah untuk mengetahui efektifitas penggunaan media LCD dalam memotivasi belajar peserta didik.

\section{METODE PENELITIAN}

Jenis penelitian ini berupa peneliatian kualitatif yaitu penelitian yang menghasilkan data deskriptif berupa kata-kata tertulis dari orang dan pelaku yang diamati (Saefudin, 2007). Objek penelitian ini adalah MA ASHRI Jember kelas XIIA, alasan pemilihan sekolah tersebut karna sudah tersedianya media LCD proyektor di masing-masing ruang kelas.

Teknik pengumpulan data penliti menggunakan beberapa Teknik yakni observasi, angket dan wawancara. Teknik obeservasi dengan objek ruang kelas XIIA, guru Bahasa Indonesia kelas XIIA, kegiatan pembelajaran kelas XIIA. Teknik wawacara dengan objek Kepala Sekolah, Tenaga Pengajar, dan Peserta didik kelas XIIA. Teknik angket dengan objek peserta didik kelas XIIA.

Analisis data pada penelitian ini berupa Kualitatif dengan menampilkan hasil presentase angket berupa angka. Adapun langkah penyajian data (1) reduksi data, merangkum data yang diperoleh sehingga memberikan gambaran yang lebih jelas, (2) Penyajian data, peneliti menampilkan data berupa teks naratif yang didukung hasil angket yang sudah diuji coba di lapangan, (3) Verifikasi, penarikan kesimpulan dan verifikasi dengan tujuan dapat menjawab rumusan masalah (Arikunto, 2006).

\section{HASIL DAN PEMBAHASAN}

Berdasarkan data uji coba yang telah dipaparkan, berikut ini disajikan hasil analisis hasil uji dengan menggunakan angket kepada peserta didik, beikut hasilnya:

Tabel 1

Penggunaan Media

\begin{tabular}{lllllll}
\hline NO & SOAL & A & B & C & D & E \\
\hline 1 & $\begin{array}{l}\text { Penggunaan media pembelajaran oleh } \\
\text { guru pada saat proses pembelajaran. }\end{array}$ & 16 & 8 & 47 & & \\
& & & & & \\
\hline
\end{tabular}

Berdasarkan keterangan kepala sekolah setiap tenaga pengajar wajib menggunakan media yang sudah disediakan serta mengembangkan media yang sudah ada. Dan pada kenyataannya tidak semua tenga pengajar menggunakan media terutama yang berkaitan dengan teknologi masa kini seperti LCD karena 
tenaga pengajar tidak memiliki kemampuan untuk menggunakannya.

Tabel 2

Pemilihan Media

\begin{tabular}{llllllll}
\hline NO & SOAL & & A & B & C & D & E \\
\hline 2 & Pemilihan Media LCD oleh guru sesuai & 49 & 13 & 9 & & \\
& $\begin{array}{l}\text { dengan materi pelajaran Bahasa } \\
\text { indonesia }\end{array}$ & & & & & \\
\hline
\end{tabular}

Penggunaan LCD pada saat proses belajar mengajar bisa membantu tenaga pengajar menyampaikan materi, seperti halnya menyiapkan satu meteri untuk digunakan selanjutnya tanpa harus menulis lagi dipapan tulis.

Tabel 3

Penggunaan Media oleh Guru

\begin{tabular}{lllllll}
\hline NO & SOAL & A & B & C & D & E \\
\hline 3 & $\begin{array}{l}\text { Guru dapat menggunakan media LCD } \\
\text { dengan baik }\end{array}$ & 63 & 4 & 4 & & \\
\hline
\end{tabular}

Pada saat praktek menggakan media LCD tenaga pengajar dapat dengan mahir menggunakanya, tetapi masih ada beberapa tenaga pengajar yang belum bisa sama sekali menggunakan. Tenaga pengajara mengguanakan aplikasi Microsoft office power point sebagai penunjang dalam menyajikan materi pelajaran.

Tabel 4

Kertersediaan Alat dan Bahan

\begin{tabular}{lllllll}
\hline NO & SOAL & A & B & C & D & E \\
\hline 4 & $\begin{array}{l}\text { Tenaga pengajar menyediakan alat dan } \\
\text { bahan untuk mendalami pelajaran }\end{array}$ & 27 & 10 & 22 & 6 & 6 \\
\hline
\end{tabular}

Keadaan sarana prasarana yang ada disekolah sudah sangat memedai, selain LCD proyektor yang sudah ada dimasing-masing kelas, area acces internet juga sudah tersedia.

Tabel 5

Efektifitas Waktu

\begin{tabular}{lllllll}
\hline NO & SOAL & A & B & C & D & E \\
\hline 5 & $\begin{array}{l}\text { Tenaga pengajar memulai dan mengakhiri } \\
\text { pelajaran tepat waktu }\end{array}$ & 34 & 14 & 18 & 3 & 2 \\
\hline
\end{tabular}

Berdasarkan buku kehadiran dan absen dengan alat, guru dating tepat waktu. Ini terbukti keika waktu penelitian dilakukan tenaga pengajar datang tepat 
waktu dan tidak keluar kelas ketiga jam pelajaran belum berakhir.

Tabel 6

Penggunaan Metode

\begin{tabular}{|c|c|c|c|c|c|c|c|}
\hline $\mathrm{NO}$ & SOAL & & $\mathrm{A}$ & $\mathrm{B}$ & $\mathrm{C}$ & $\mathrm{D}$ & $\mathrm{E}$ \\
\hline 6 & $\begin{array}{l}\text { Tenaga pengajar } \\
\text { beberapa metode }\end{array}$ & menggunakan & 7 & 19 & 33 & 3 & 9 \\
\hline
\end{tabular}

Tenaga pengajar menerangkan bahwa menggunakan beberapa metode selain ceramah dalam kegiatan pembelajaran, seperti halnya diskusi, tanya jawab dan lain-lain.

Tabel 7

Penggunaan Model Pembelajaran

\begin{tabular}{lllllll}
\hline NO & SOAL & A & B & C & D & E \\
\hline 7 & Tenaga pengajar menggunakan & 8 & 11 & 32 & 6 & 14 \\
& permainan dalam pembelajaran & & & & & \\
\hline
\end{tabular}

Dalam kegiatan belajar mengajar terkadang tenga pengajar mengajar peserta didik untuk bermain kuis dan memberikan hadiah, hal ini bertujuan agar peserta didik tidak jenuh di kelas karena berada di kelas dengan waktu yang cukup lama.

Tabel 8

Penggunaan Model lain

\begin{tabular}{lllllll}
\hline NO & SOAL & A & B & C & D & E \\
\hline 8 & Tenaga pengajar menggunakan & 2 & 1 & 13 & 4 & 20 \\
& perubahan posisi duduk siswa & & & & & \\
\hline
\end{tabular}

Seperti halnya keterangan di tabel sebelumnya, perubahan posisi duduk di maksudkan agar suasana kelas tidak membosankan, selain itu agar siswa yang biasanya duduk dibagian belakang merasakan posisi bagian depan yang biasa didominasui peserta didik yang aktif. Tapi di lapangan tenaga pengajar jarang melaksanakan perubahan posisi duduk karena memerlukan waktu yang cukup banyak sedangkan waktu untuk pembeljaran sangat terbatas.

Tabel 9

Keadaan Kelas

\begin{tabular}{llllllll}
\hline NO & SOAL & & A & B & C & D & E \\
\hline 9 & $\begin{array}{l}\text { Tenaga } \\
\text { siswa }\end{array}$ & pengajar berinteraksi dengan & 50 & 6 & 11 & 2 & 2 \\
\hline
\end{tabular}


Interaksi antara tenaga pengajar dengan peserta didik sangatlag diburuhkan di dalam kelas, karena tenaga pengajar harus punya kedekatan dengan peserta didik, dengan begitu adanya kedekatan membuat peserta didik merasa nyaman di kelas sehingga materi yang disampaikan mudah dipahami. kenyataan di lapangan tenaga pengajar selalu melakukan ini hampir setiap pertemuan.

Tabel 10

Efektifitas Media

\begin{tabular}{lllllll}
\hline NO & SOAL & A & B & C & D & E \\
\hline 10 & $\begin{array}{l}\text { Peserta didik mudah memahami materi } \\
\text { dengan menggunakan LCD }\end{array}$ & 24 & 29 & 15 & 3 & \\
\hline
\end{tabular}

Penggunaan media LCD dapat merangsang motivasi siswa karena materi yang ditampulkan berupa audio visual, dimana peserta didik yang memiliki gaya belajar visual dan audio sama-sama mudah memahami. Hal ini terbukti ketika kegiatan penelitian dilakukan, siswa merasa sangat antusias dan senang pada saat guru menggunakan LCD. Hamalik (1986) mengemukakan bahwa pemakaian media pengajaran dalam proses belajar mengajar dapat membangkitkan keinginan dan minat yang baru, membangkitkan motivasi dan rangsangan kegiatan belajar, dan bahkan membawa pengaruh-pengaruh psikologis terhadap siswa. Dari tabel hasil angket kepada peserta didik di atas, dapat disimpulkan bahwa penggunaan media LCD di MA ASHRI Jember kelas XIIA dapat memotovasi siswa. Berdasarkan kesimpulan dari tenaga pengajar bahwa setiap siswa mempunyai keinginan untuk giat belajar, namun banyak factor yang mempengarui peserta didik sehingga menjadikan malas. Hal ini menjadi tugas tenaga pengajar dan orang tua untuk bisa memotovasi.

Adapun faKtor pendukung dan penghambat penggunaan LCD proyektor di MA ASHRI Jember kelas XIIA adalah sebagai berikut (1) factor pendukung: tenaga pendidik yang memiliki keahlian dari pelaksanaan pelatihan, kesadaran orang tuan terhadap Pendidikan, tempat belajar yang kondusif dan bersih, sarana dan prasarana yang lengkap. (2) factor penghambat: masih ada tenaga pendidik yang belum bisa mengopersaikan teknologi sehingga tidak dapat menggunakan media LCD, mash minimnya pelatihan untuk tenaga pengajar terkait penyajian materi yang menarik, masih sulitnya tenaga pendidik untuk menggunakan metode baru.

\section{SIMPULAN}

Dari paparan diatas dapat ditarik kesimpulan, guru dapat membuat mendesain media dengan variasi dan lebih menarik, karna didukung teknologi. Penyajian materi yang meningkatkan minat siswa untuk belajar, kelas yang kondusif, daya serap peserta didik yang lebih tinggi. 


\section{DAFTAR PUSTAKA}

Arikunto, S. (2006). Prosedur Penelitian. Jakarta: Rineka Cipta.

Azwar, S. (2007). Metode Penelitian. Yogyakarta: Pustaka Pelajar,.

Hamalik, O. (1986). Media Pendidikan. Bandung: Alumni

Sudjana, N. (2000). Dasar-Dasar Proses Belajar Mengajar. Bandung: PT. Sinar Baru Algensindo.

Suryanto, M. (2005). Multimedia. Yogyakarta: Andi offset. 